TITLE:

\title{
Work in Progress: Proposal for Comparative Studies on East Asia STS
}

$\operatorname{AUTHOR}(\mathrm{S})$ :

Shineha, Ryuma; Ema, Arisa; Tsukahara, Togo

\section{CITATION:}

Shineha, Ryuma ... [et al]. Work in Progress: Proposal for Comparative Studies on East Asia STS. East Asian Science, Technology and Society: an International Journal 2010

\section{ISSUE DATE:}

2010-05

URL:

http://hdl.handle.net/2433/120330

\section{RIGHT:}

The original publication is available at www.springerlink.com; この論文 は出版社版でありません。引用の際には出版社版をご確認ご利用くだ さい。; This is not the published version. Please cite only the published version. 


\section{Work in Progress: Proposal for Research on East Asia STS, Comparison of the Issues in Each Research Community.}

\section{Ryuma Shineha1.4.5, Arisa Ema ${ }^{2.4 .5}$, Togo Tsukahara ${ }^{3}$}

1. Graduate School of Biostudies, Kyoto University

2. Graduate School of Arts and Sciences, University of Tokyo

3. Graduate School of Intercultural Studies, Kobe University

4. Research Fellow of the Japan Society for Promotion of Science

5. Science, Technology and Society Network Japan

STS research has recently spread to East Asia, and some new frameworks of STS research can now be observed. East Asian Science, Technology and Society: an International Journal (EASTS journal), has been published since 2007. In "How Far Can East Asian STS Go? A position paper," Daiwie Fu (2007) made several points regarding the development of East Asian STS:

"East Asian STS will offer fresh STS perspectives because of its special local experiences, shared cultural and colonial histories, similar geological and meteorological makeup, and similar global positions" (p.13)

"EASTS studies are indeed different from simply applying Western STS perspectives to East Asian 'area studies" " (p.5)

$\mathrm{Fu}$ also mentioned the importance of social practice and local contexts for science and technologies in East Asia:

"...in contrast to super-rich, modern technologies, in East Asia we might like to pay more attention to the appropriate, the small, and the creole" (p.12)

According to $\mathrm{Fu}$, EASTS should not be the mere application of western STS to East Asian case studies. EASTS should be a provider of fresh STS perspectives that take into consideration the practices of each local context.

Many STS scholars in East Asian countries agree that EASTS is not the mere application of western STS theories, and accept the value of development of new frameworks of EASTS. However, we need to specify the questions, such as "What is an East Asian perspective?" and "What is the first step for action?" STS has spread rapidly, and at the same time each research community has set up its own journals and organizations/institutions embedded in their own culture. We should act with an understanding of commonalities and differentiators between each community before cooperation. 
To foster deeper mutual understanding and distinguish between each community's characteristics, a team of researchers from STS Network Japan” (STSNJ) would like to present a proposal for an East Asian STS comparative research project. STSNJ is one of several STS research groups in Japan, and was established in 1990 by Hideto Nakajima and his colleagues. STSNJ is a separate organization from the Japanese Society for Science and Technology Studies (JSSTS). STSNJ is an organization for information sharing, and an arena for discussion, particularly for young STS scholars. On the basis of this network, we hope to establish an East Asian network, particularly of young researchers.

Our proposal is to carry out comparative research on each community's STS research by means of qualitative/quantitative analysis. One comparative example is discussed in this report, and it is the result of an analysis of the Japanese STS journal and the EASTS journal.

\section{Method and target of analysis}

The purpose of this analysis is to distinguish the tendencies and characteristics of each community's research in STS.

In this analysis, the Japanese and the EASTS journal were considered. The Journal of Science and Technology Studies (JSTS) has been published annually since 2002, mostly in Japanese. So far, 7 issues containing 131 articles, including 22 book reviews, have been published. The EASTS Journal was first published in 2007. Eight issues have now been published, containing 93 articles, including 31 book reviews, excluding online first articles. All articles are written in English, and abstracts in several languages are attached.

In this report, we conducted network analysis focused on the co-occurrence of keywords (co-words) in article titles and abstracts, in order to grasp topics, keywords in context, and the relationships between topics and keywords. Although several problems have been discussed in previous studies (Leydesdorff 1997), co-words and the network structure of co-words have been widely recognized as carriers of meaning and indicators of words in context (Callon et al., 1983; Callon et al., 1991; Stegman and Grohmann 2003; Leydesdorff and Hellstein 2005; 2006). In addition, words in titles and abstracts represent contents and can be seen as the identification markers of articles (Mullins et al., 1988; Braam et al., 1991). The method of network analysis in this report depends on previous studies by Leydesdorff and Hellstein (2005; 2006). In this analysis, Salton's cosine, which is one of the major similarity indexes, was calculated as the similarity 
index (Salton and McGill 1983; Jones and Fornus 1987). Networks are described by Pajek (Batageli and Mrvar 1998). The visualizations are based on the Kamada and Kawai algorithm (Kamada and Kawai 1989). Centrality was shown based on betweenness (Freeman 1979).

The frameworks and target scientific fields of each article were also investigated, in order to interpret our results and provide additional indicators.

\section{Biases and Limitations}

First, there may be a bias arising from special feature issues. For example, the JSTS journal featured "science communication" in volume 5, and "nanotechnology" in volume 6. However, the choice of topics can be regarded as representative of the features of each country's STS.

Second is the limited number of journals compared. In this report, only two journals were analyzed. However, there are several other STS journals in East Asia. For example in Japan, another STS journal, the Japan Journal for Science, Technology and Society, has been published since 1992. We can point out some trends, but excessive generalization should be avoided. In order to hold general discussions of the understanding of STS in East Asian countries, the characteristics of other journals in Taiwan, Korea, and China should be analyzed using this method. Thus this report should be read as a first trial for further discussion.

Third is a technical matter. In quantitative text analysis, several preparations for analysis are important, including making corpus, unification of words, and stemming. Although we conducted some preparations, such as rewording from plural to singular, this remains at a rough level.

Even though there are some limitations, due to the preliminary character of our analysis, and although this survey remains at a rough level at this stage, we believe it offers an outline for comparison, and a map of major research topics and their contexts in the JSTS and EASTS journals.

\section{Results}

Figure 1 illustrates a network analysis, focusing on keywords in titles, of the JSTS journal. In this analysis, the top 109 keywords, which appeared more than twice in titles of the whole article set, including book reviews, were selected as variables. For the analysis of titles in the JSTS journal, the threshold of cosine was set to 0.37. 


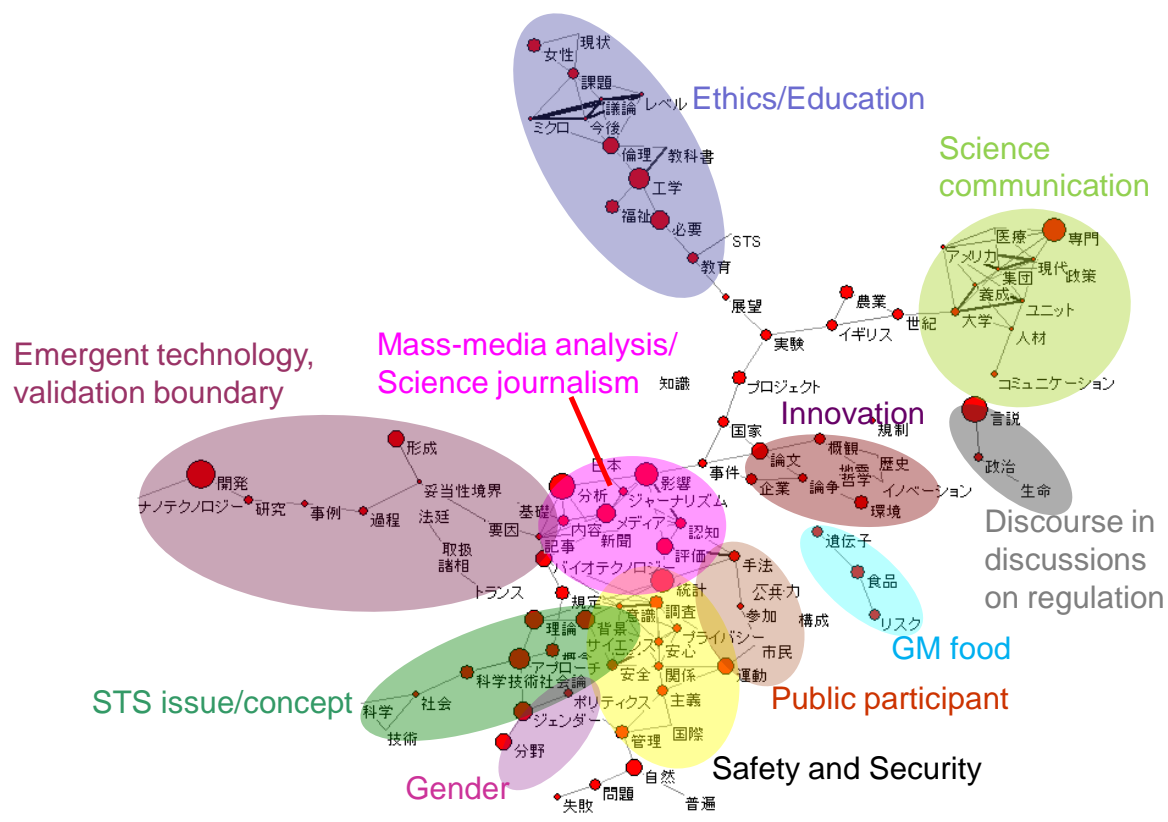

Figure 1. Cosine map of 109 words used more than twice in JSTS article titles (Cosine $\geq$ $0.37)$

It was found that there are recurring topics: "STS: issue/concept," "emergent technology, validation boundary," "mass-media analysis/science journalism," "gender," "public participation," "safety and security," "gm food," "innovation," "discourse in discussions on regulation," "ethics and education," and "science communication." In addition, it was found that there are many articles which take up advanced science fields such as nuclear power, bio/medical science (e.g. human genome project), nanotechnology, information science, ecological science, environmental science, and so on. Concerning frameworks, the "validation-boundary" concept discussed by Yuko Fujigaki (2003) was often taken up.

Figure 2 illustrates a network analysis, focusing on keywords in titles, of the EASTS journal. In this analysis, the top 67 keywords that appeared more than twice in titles of the whole article set, including book reviews, were selected as variables. For the analysis of titles in the EASTS journal, the threshold of cosine was set to 0.35 . 


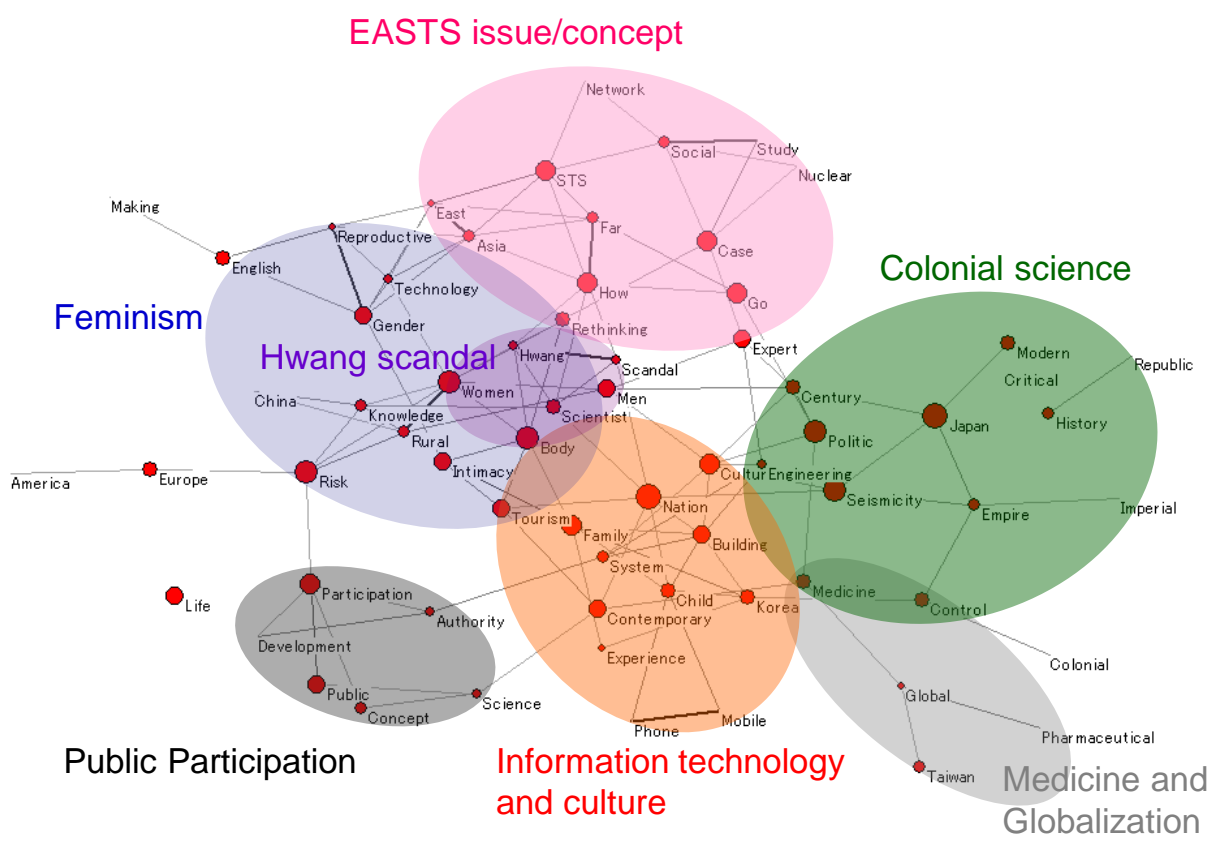

Figure 2. Cosine map of 67 words used more than twice in EASTS article titles (Cosine $\geq$ $0.35)$

It was found that the following are regular topics: "EASTS: issue/concept," "colonial science," "feminism," "Hwang scandal," "public participation," "information technology and culture," and "medicine and globalization."

A network analysis of keywords in abstracts was also conducted for the EASTS journal, in addition to the analysis of keywords in titles (Figure 3). In this analysis, the top 124 frequent keywords, which appeared over three times in abstracts, were selected as variables. For the analysis of abstracts in the EASTS journal, threshold of cosine was set 0.515 . 


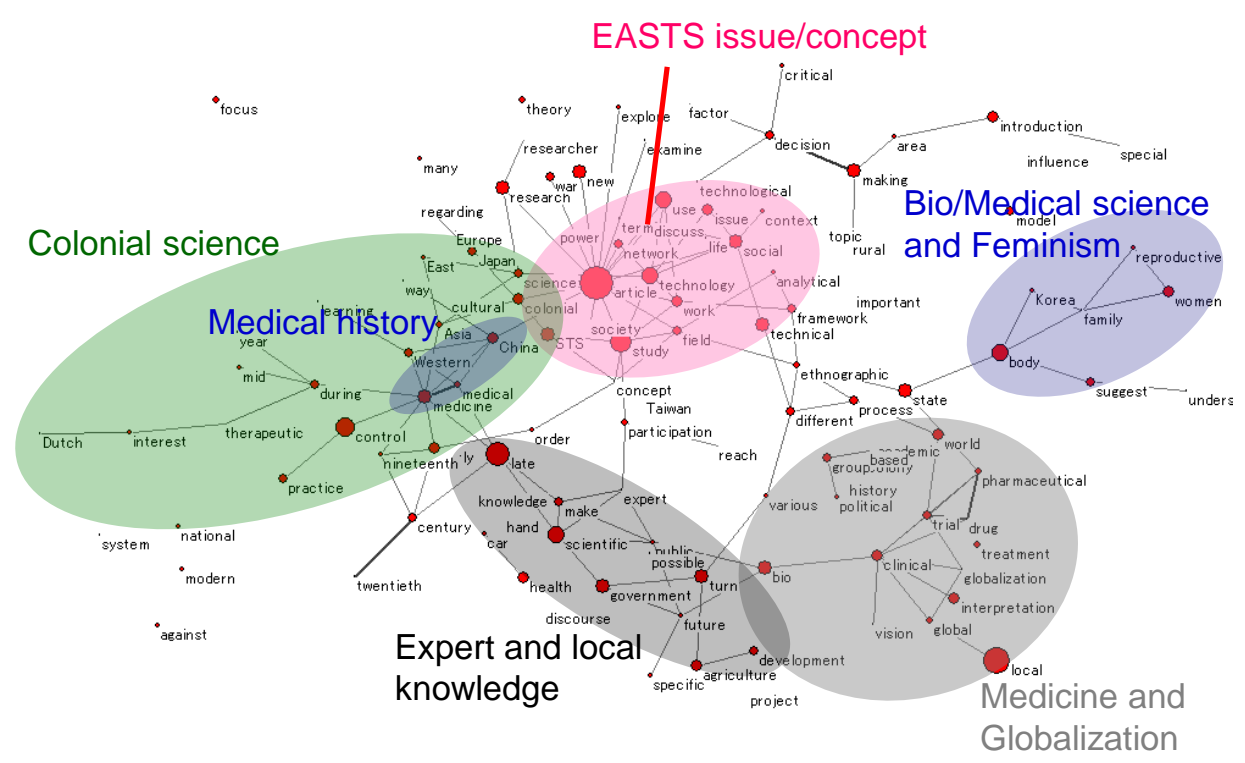

Figure 3. Cosine map of 124 words used more than three times in EASTS abstracts (Cosine $\geq 0.515)$

Considering the results of Figure 2 and Figure 3, it was found that issues related to keywords such as the body, gender, and women appeared with the topics on "bio/medical science" (e.g. Hwang scandal, reproductive technique). Interestingly, this indicates that "bio/medical science" was discussed in the context of "feminism" and vice versa. The theme concerning "expert and local knowledge" was discussed in the context of public participation in some cases, and several investigations of medical history were conducted as colonial science studies. The topics "medicine and globalization" and "colonial science" are also found in this analysis of keywords in abstracts.

\section{Summary and Discussion: Differentiators and Commonalities}

The result of our comparison of the contents of the JSTS and the EASTS journal is summarized in Figure 4. 

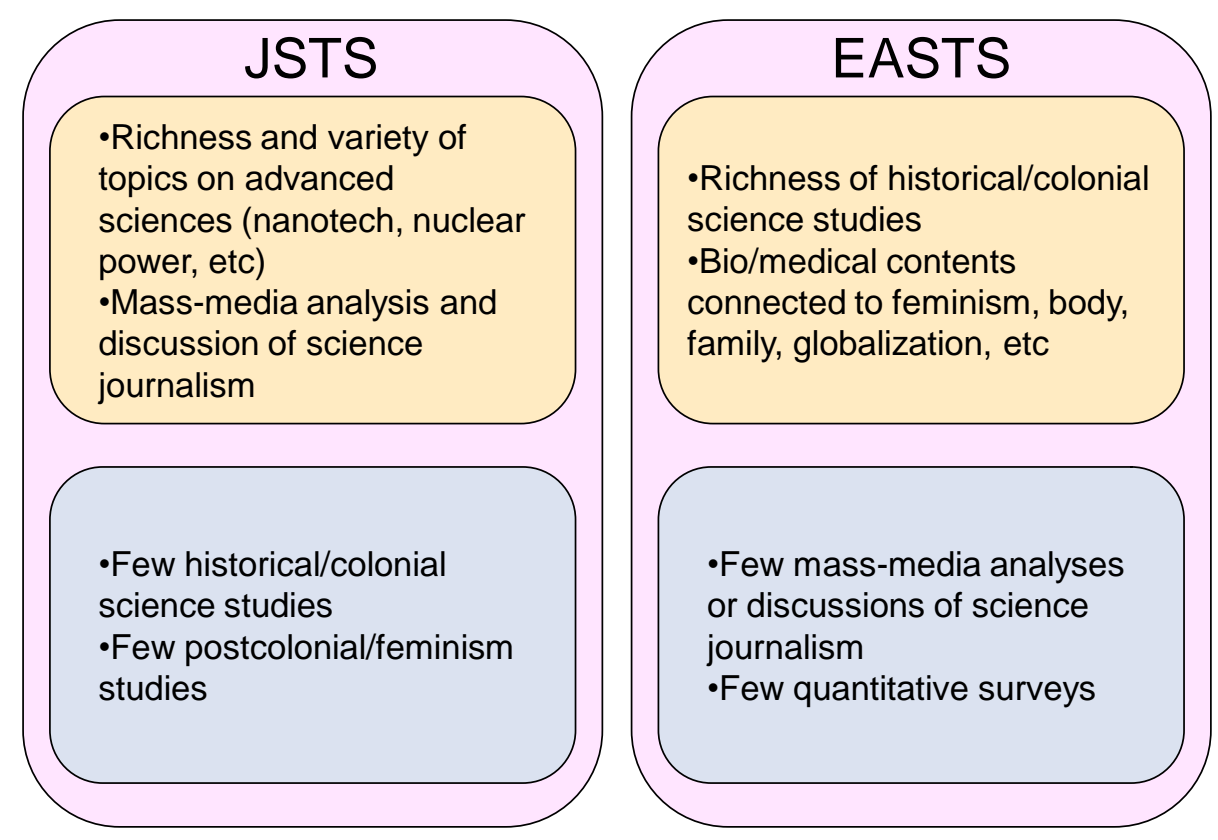

Figure 4. Summary of comparison of the JSTS and the EASTS journals

A variety of topics on advanced sciences (nuclear power, nanotechnology, etc.) can be pointed out as a defining feature of the JSTS journal. Conversely, discussions of mass-media analysis (particularly on quantitative analysis) and science journalism are not seen in the EASTS journal. The JSTS journal lacks articles on historical research and investigations of colonial science. One possible reason for the lack of historical studies may be a local division of labor with the History of Science Society of Japan. If this hypothesis is correct, it seems that this result indicates a separation between history of science and STS scholars along the lines of respective journal communities in Japan. At the same time, the discussion of feminism and postcolonial STS are minor topics in the JSTS journal. In JSTS volume 7, a special topic "women and science" was taken up. However, the articles in that issue were largely limited to showing data for the discussion of gender problems in science, such as the ratio of women scientists. As one of the most significant features in terms of frameworks or concepts, the validation-boundary suggested by Yuko Fujigaki (2003) is highlighted.

The EASTS journal exhibits a richness of historical studies and investigation of colonial science, which contrasts with the JSTS journal. At the same time, several ethnographic studies to investigate local knowledge were observed as part of this historical approach. Another prominent feature is the richness of content on "bio/medical science" and discussions on "bio/medical science" connected to keywords 
and concepts such as feminism, the body, family, and globalization. While there is a richness of historical research and content on feminism, there are few mass-media analyses, discussions of science journalism, or quantitative surveys. This also shows a contrast with the JSTS journal.

Although it seems a truism, it can be summarized that there are significantly different tendencies in article topics and fields between the JSTS and EASTS journals. This indicates that the two journals have different interests, and that there are differences in STS culture in other countries' journal communities, such as those in Korea, Taiwan, and China. It will be necessary to investigate the journals of other Asian countries to map East Asian STS comprehensively, and open a new field of more general discussion on comparative studies of East Asian STS.

The two journals do share a common direction: Both academic research and practice are regarded as an important theme. In addition, there are common interests and frameworks such as "public participation," "local knowledge," "actor network theory," etc. However, these are not only common in the East Asian context, but also common in the global STS context. Tsukahara (2009) suggested that this situation in Japan was a symptom of the colonial and Western-dependent character of intellectuals. This links in with Fu's position that EASTS aims not just to apply Western STS perspectives to Asian cases (Fu, 2007). Therefore, directions for establishing and considering EASTS should continue to be discussed.

\section{Proposals}

We have demonstrated that we can distinguish different tendencies between the JSTS and the EASTS journal, and we call for research cooperation for the investigation of the STS journals of other Asian countries, and for more comprehensive and general discussions. For future effective cooperation, and STS's own reflexivity, and the enhancement of our mutual understanding through STS, it will be essential to add analyses of the STS journals of the Korean, Taiwanese, and Chinese research communities. Comparison of these journals will more vividly show the features of each STS culture and community in the East Asia region.

Thus we would like to make three proposals for discussion and research on STS in East Asia, to promote more active international cooperation in the future.

1. Investigate and discuss the possibility of new East Asian STS theories, not just applying Western theories

2. Grasp differentiators and commonalities between the STS communities of each country (this would be a clue to finding new perspectives) 
3. Share STS issues found in each East Asian country, and consider effective means of cooperation

In our opinion, the differences between STS in each country present an opportunity for cooperation, using each other's strong points effectively. Active cooperation between STS scholars in East Asian countries will provide more fruitful insights into both EASTS and indigenous STS perspectives. In order to cultivate these fruits, we hope for and need collaboration from STS scholars in each Asian country.

As the context for future cooperation, the 35th 4S Annual Meeting will be held jointly with Japanese Society for Science and Technology Studies in Tokyo in August 2010. The special theme of this meeting is "STS in Global Contexts." It will be a good opportunity to consider "What is East Asian STS?" Thus, we would like to call for collaboration with our East Asian STS colleagues.

\section{Acknowledgement}

This report is based on a presentation at the 4th East Asian STS Young Scholar's Workshop 2009, in Kobe. In the workshop, we received valuable comments from Prof. Song Sang-Yong, Prof. Hideto Nakajima, and Prof. Wen-Hua Kuo. The proposals in this report for future cooperation were designed by the STS Network Japan.

\section{Reference}

Batagelj, V.a.M., A. (1998). Pajek - A program for large network analysis. Connections, 21(2), 47-57.

CALLON, M., J.-P. COURTIAL, W. A. TURNER, S. BAUIN. (1983). From translations to problematic networks: An introduction to co-word analysis. Social Science Information, 22, 191-235.

CALLON, M., J. P. COURTIAL, F. LAVILLE. (1991). Co-word analysis as a tool for describing the network of interactions between basic and technological research: The case of polymer chemistry. Scientometrics, 22(1), 155-205.

Freeman, L.C. (1979). Centrality in social networks conceptual clarification. Social Networks, 1(3), 215-239.

Fu, D. (2007). How Far Can East Asian STS Go? A position paper. East Asian Science, Technology and Society: an International Journal, 1(1), 1-14.

Fujigaki, Y. (2003). The Public Ethic and the Spirit of Specialism. University of Tokyo Press.

JONES, W.P., G. W. FURNAS. (1987). Pictures of relevance: A geometric analysis of similarity measures. Journal of the American Society for Information Science, 
$36(6), 420-442$.

KAMADA, T., S. KAWAI. (1989). An algorithm for drawing general undirected graphs. Information Processing Letters, 31(1), 7-15.

LEYDESDORFF, L. (1997). Why words and co-words cannot map the development of the sciences. Journal of the American Society for Information Science, 48(5), 418-427.

LEYDESDORFF, L., I. HELLSTEN. (2005). Metaphors and diaphors in science communication: Mapping the case of 'stem-cell research'. Science Communication, 27(1), 64-99.

LEYDESDORFF, L., I. HELLSTEN. (2006). Measuring the meaning of words in contexts: An automated analysis of controversies about 'Monarch butterflies,' 'Frankenfoods,' and 'stem cells'. Scientometrics, 67(2), 231-258.

SALTON, G., M. J. MCGILL. (1983). Introduction to Modern Information Retrieval. Auckland, etc., McGraw-Hill.

STEGMANN, J., GROHMANN, G. (2003). Hypothesis generation guided by co-word clustering. Scientometrics, 56(1), 111-135.

Tsukahara, T. (2009). Introduction (1): Japanese STS in Global, East Asian, and Local Contexts. East Asian Science, Technology and Society: An International Journal, online first. 